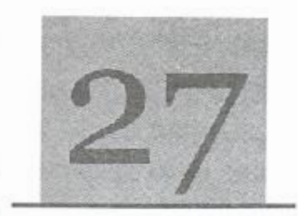

\title{
Efficiency of different traps for silver catfish fishery and its aquaculture implications in the face of climate change
}

\author{
Anwa-Udondiah, E. P./ Anyanwu P. E. / Akintayo I. A.
}

\section{Abstract}

Clinate change has the potential to severely impact coustat and iniand environments and cosystems, and by extension fisheries und aquaculture. Coastal regions of the world are already experiencing flooding due to rise in sea level. In recent limes, scilinization of coastal areas due to flooding from storm surges and high tidal influence has been observed. Aquaculure is a fast growing agri-business venture in Nigeria presently and many coastal communities derive their livelihood from it. The culture of fresh water fish species that are very sensitive to high salinity may be threatenad leading to mortality of stocked fish and loss of livelihood for coastal population. Consequently, there is urgent need for development and domestication of the Silver catfish. Chrysichtinys nigrodigitatus that can tolerate higher salinity more than Mudcatfish (Clarias gariepimus). This will help mitigate the impact of salinization of coastal areas arising from sea water fooding on culture of fresh water fish species.

Keywords: Climate change, Silver calfish. Chrysichthys nigrodigitatus

\section{Introduction}

Ylimate change has the potential to severely impact coastal and inland environments and ecosystems. All rural communities need to be aware of the potential impacts of climate

change, and take measures to adapt, so that they can become resilient to thesc changes. Only by identifying the risks associated with climate change, can communitics initiate a plan that prepares them to adapt, and thus manage the social, cconomic, and environmental impacts of climate change on their communities (The WorldFish Center, 2012).

Fisheries and aquaculture are vulnerable to climate change (Timmers, 2012). The Fourth Assessment Report of the Intergovernmental Panel on Climate Change (IPCC) in 2007 highlighted the vulnerability of Africa, as a whole, $t)$ climate change and variability. Fishcrics and aquaculture production are exposed $t 0$ various facets of climate change, resulting in complex impact pathways (Timmers, 2012). According to Vermeulen $c 1$ al: $(2012$ ) the impacts of global climate change on food systems are expected to be widespread, complex, gcographically and temporally variable, and profoundly influenced by socioeconomic conditions.

Winograd (2005) defined adaptation as a system's ability to adapt to changes in the climate, to reduce the potential damage, to capitalize on opportunities and to cope with the consequences. In the context of aquaculture, a promising intervention and adaplation would be the development and culture intensification of culturable euryhaline fish species that can thrive in the increasing saline conditions of coastal communitics. a fall-out of climate change. Intrusion of sea-water into fresh water sources and cusystems has been observed in some coastal communities in Nigeria (Awosika, 1995; Okali and Eleri, 2004; Lyigue and Agho, 2007).

In Nigeria, the aquaculture industry is dominated by the culture of Clarias gariepinus and Heterobranchus sp, which are purcly fresh water species. However, for coastal communities where there have been cases of salt intrusion as a result of climate induced changes, the

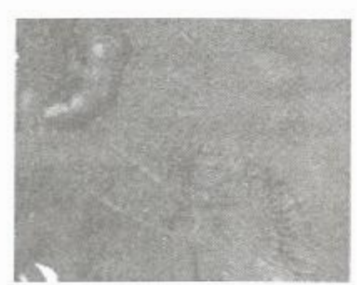

Plate I: Preparing a trap.

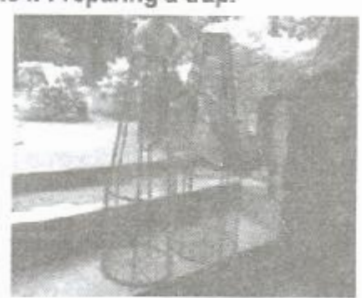

Plate II: The finished traps.

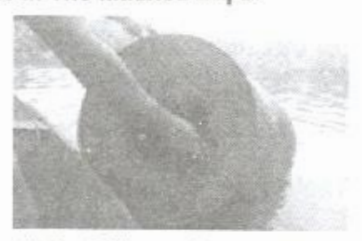

Plate III: Installing a drum trap at the mangrove fringes (esuk Nwaniba).

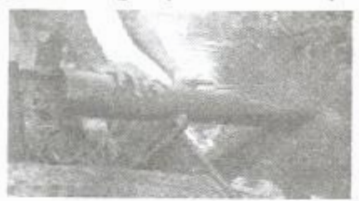

Plate IV: Retrieving PVC pipe...

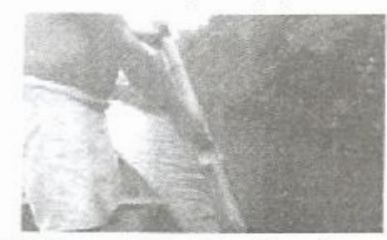

Plate V:... and bamboo from the coastal edge of Ifiayong River. 
culture of these fresh water calfishes may be threatened. Ogunsheye and Sogbesan (2005) studied the effect of different salinity levels ranging from 0.2 to $4.2 \mathrm{ppt}$ on the growth and survival of Clarias gariepinus fiy. From the study, the survival and weight gain decreased with increase in salinity. Also, 100\% mortality was recorded for hybrid cattish fingerlings that were exposed to higher salt concentrations of 10 and 12 ppt by Awotongha ct al. (2011). Indicating that if alternative culturable fish is not provided, farms in these regions may close up and farmed fish may become scarce in these parts of the country.

Chrysichthys nigrodigitatus is a euryhaline cattish that thrives in both fresh and brackish waters mainly in West Africa (Anyanwu, 1991; Risch and Vreven, 2007). According to FAO (1982), it is found in salinity levels ranging from 0 to $26 \mathrm{ppt}$. In Nigeria, C. nigrodigitatus is a highly valued food-fish and is among the dominant fishes of commercial catches as well as culturable fish species from the wild (Ezenwa et al.; 1986, 1990). A monoculture study of the catfish, C. nigrodigitatus was carried out in the late 70's in brackish water ponds off the shores of Lagos lagoon, and under varying salinity fluctuations (FAO, 1982). It was recommended that since the Nigerian coast was characterized by extensive stretches of swamps and shallow areas not utilized for any other profitable form of agriculture, that the Silver catfish could be grown in these brackish waters, and therefore create a unique catfish industry for the coastal waters of Nigeria.

The purpose of this paper is to present the outcome of a pilot study undertaken to investigate the likelihood of developing the culture of the Silver cattish by harnessing the strategies of its behavioural tendencies in its natural environment as an effective climate-smart practice. In particular, it seeks to draw attention to appropriate gears that may be utilized for an efficient trapping of broodstock of the Silver catfish, C. nigrodigitatus at no risk or damage to the fish.

\section{Materials and Method}

- Passive fishing gears - Four types of traps were installed at the mangrove fringes of Ifiayong River located at Ifiayong Usuk in Nwaniba village in Uruan I.ocal Government Area of Akwa lbom Statc. The traps comprised twenty-five pieces each of drum trap, netted conical trap, pve pipes and bamboo traps whose processes of preparation, installation and retrieval are depicted in Plates I to V. Seven days later another boat trip was made to check the traps and retrieve them from the different points along the River edges in the company of a fisherman and his son.

- Morphometric analysis - Body length and weight measurements of broodstock caught in the drum and netted conical traps were taken. The total length was taken from the tip of the snout to the end of the caudal fin while the body weight was taken with a Camry scale. Specimens were ventrally dissected and their gonadal states investigated.

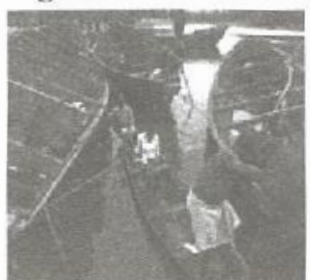

Plate VI: Boat trip with fisherman and son.

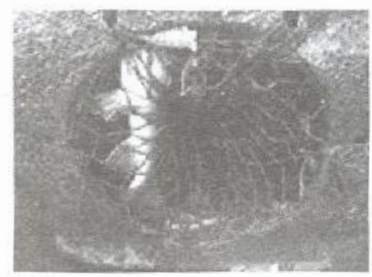

Plate VII: A couple of $C$. nigrodigitatus in drum trap,

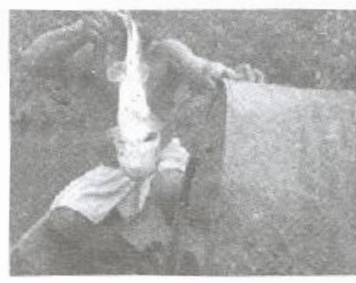

Plate VIII: Retrieval of male C. nigrodigitatus from drum trap.

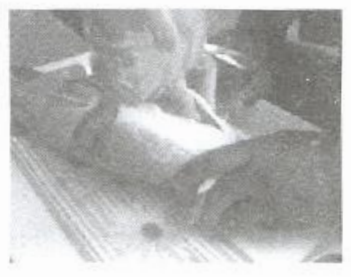

Plate IX: Dissection of $C$. nigrodigitatus

\section{Results and Discussion}

The passive gear that gave the best results in terms of sizes and sexual maturity of $C$. nigrodigitatus caught was the drum trap. The largest gravid male and female Silver catfish that were trapped in one of the drums had total lengths of $55 \mathrm{~cm}$ and $39 \mathrm{~cm}$ respectively. The survey trip embarked upon with the fishermen in order to retrieve the fishing gears, the retricval, and the dissection of a specimen of C nigrodigiiatus are shown in Plates VI to IX respectively. The outcome of the morphometric studies carried out on nine Silver catfish broodstock are shown below in Table 1.

Table 1: Morphometrics of C. nigrodigitatus broodstock

\begin{tabular}{l|l|l|l|l|l|l|l}
\hline No. & \multicolumn{1}{|c|}{ Trap } & Wt $(\mathrm{g})$ & $\mathrm{SL}(\mathrm{cm})$ & $\mathrm{FL}(\mathrm{cm})$ & $\mathrm{TL}(\mathrm{cm})$ & \multicolumn{1}{|c|}{ Sex } & \multicolumn{1}{|c}{ Remarks } \\
\hline 1 & Drum & 1200 & 49.5 & 54.4 & 60.5 & Female & Presence of immature oocytes \\
\hline 2 & Drum & 2400 & 55.5 & 60.4 & 66.0 & Male & Enlarged head \\
\hline 3 & Drum & 2000 & 56.5 & 61.0 & 67.8 & Female & Presence of immature oocytes \\
\hline 4 & Drum & 700 & 32.0 & 35.0 & 42.0 & Female & Presence of immature oocytes \\
\hline 5 & Drum & 1400 & 44.0 & 48.4 & 55.0 & Male & Enlarged head and elongated papilla \\
\hline 6 & Drum & 600 & 32.6 & 37.1 & 39.0 & Female & Presence of eggs \\
\hline 7 & Netted cone & 300 & 20.4 & 24.5 & 30.2 & Male & Immature \\
\hline 8 & Nelted cone & 550 & 30.3 & 34.7 & 40.1 & Male & Immature \\
\hline 9 & Netted cone & 325 & 22.6 & 27.9 & 33.8 & Female & Presence of eggs \\
\hline
\end{tabular}

Key: Wi -weight; SL - standard length, FL - forkiength; $l \mathrm{~L}$ - totul hength

Collection of C. nigrodigizatus by attracting sexually mature couples into passive fishing gears is a first step towards its propagation. Traps as stated by Emmanuel (2008) are simple and passive fishing gears that allow fish to enter and then make 
it hard for them to escape. This method was preferred as it does not hurt the fish. The fish that were trapped in the different passive gears employed were devoid of wounds. The use of hooks to catch them had been observed in the past to give rise to opportunistic infections resulting in death usually. It was obscrved that the sizes of $C$. nigrodigitatus caught were to a large extent dependent on the types of gear utilized. For instance, the tubular gears probably due to their small diameters naturally attracted smaller sized catfish. $\Lambda$ s the inlerest was in devising a better mode of collecting gravid couples, the drum trap was adjudged the best. In addition, the drum trap was highly selective of gravid silver catfish. A similar observation was made by Emmanuel and Olojede (2010) with the wire basket trap which was highly selective for the crab, Callinectes amnicola. The effectiveness of the trap made it a good small-scale fishing gear.

\section{Conclusion}

The aquaculture industry in Nigeria is of economic importance nationally, therefore adaptation plans for climate change in the coastal communitics need to be taken into account by broadening the scope of culture species to include fishes that can thrive in a brackish environment, such as C. nigrodigitatus. Appropriate gear such as the drum trap for the collection of gravid broodstock for propagation and subsequent culture is a necessary intervention.

\section{REFERENCES}

Anyanwu, P. E. (1991): Influcnce of salinity on the survival of fingerlings of the estuarine calfish, Chrysichthys nigrodigitatus. Aquaculture 99: $157-165$.

Awosika, L. F. (1995): Impacts of global climate change and sea level rise on coastal resourccs and energy development in Nigeria. In: Unolu, J. C. (ed). Global Climate Change: Impact on Encrgy Development. DamTech Lid. Nigeria.

Awotongha, J. G., Uwgemorabong, U. G. and Nwadukwe, F. O. (2011): Mortality of hybrid catfish (C. gariepinus $\mathrm{x}$ H. bidorsalis) fingerlings at varying salinity levels. Journat of Fisheries lnternational, 6:71 74

Emmanucl, B. E. (2008): The fishery and bionomics of the swimming crab, Callinectes amnicola (De Rocheburnc, 1883 ) from a tropical lagoon and its adjacent creek. South-west, Nigeria. Jownal of Fisherie's and Aquatic Science. 3(2): 114

, E. T. Olojede. (2010): Comparative studies on the catch selectivity of galvanized wire gauze trap from fresh and brackish water tropical creeks in south-western Nigeria. Jounal of Life and Physical Sciences, acta SATFCH 3(2): 91 - 101

Kusemiju, K. and Olaniyan, C. I. O. (1986): Comparative studies of the catfish, Chrysichthys nigrodigitatus (I.) in three isolated geographical areas in Nigeria for breeding purpose. Agtat. Res, Afr. Reg. I. 1: 258-262.

Alegbeleyc, W. O., Anyanwu, P. E. and Lzukwu, E. O. (1990). Culturable fish secds in nigerian coastal waters. a rcscarch survey (Second Phasc: 1986-1989). NOMMR Tech, 66, 37.

FAO. (1982): Coastal aquaculture: development perspectives in Africa and case studies from other regions. CIFA Technical Paper. 272.

IPCC. (2007): Climale Change 2007: The Physical Science Basis. Contribution of the Working Group I to the Fourth Assessment Report of the Intergovemmental Panel on Climate Change [Solomon, S., D. Qin, M. Manning (eds.)].

Ogunsheye, J. O. and Sogbesan. A. O. (2005): Effect of sainity on growth and survival of Clarias gariepinus: Claritala fry. In Proceedings, 19 th FISON Annual Conference, Nov. 20-Dec. 03 2004, Ilorin.

Okali, D. and Eleri, E. O. (2004): Climate change and Nigeria: a guide for policy makcrs, a publication of the Nigerian Environmental Study Action Tcam (NEST).

Risch, L. and Vreven, E. J (2007): Clarotcinae. p. 607-629. In M.L.J. Stiassny, G.G. Teugels and C.D. Hopkins (eds.) The fresh and brackish water fishes of Lower Guinea, Wcst-Central A frica. Volume I. Collection Faune et Flore tropicales 42. Institut de Recherche pour le Dćvcloppement. Paris. France, Musćum National d'Histoire Naturellc, Paris, France, and Musée Ruyal de l'Afrique Centrale, Tervuren, Belgium. $800 \mathrm{pp}$.

The WorldFish Center. (2012): Responses to climate change: Adaptation pathways to change. Penang, Malaysia. Project $2012-25$.

Timmers, B. (2012): Impacts af Climate Change and Variahility on Fish Valuc Chains in Uganda. The WorldFish Center, Penang, Malaysia. Project Report No 2012-18.

Winograd, M. (2005): Capacity strengthening in climate change vulnerability and adaptation strategy assessments. Background on framcworks, methodologies and tools for vulnerability and adaptation assessments: How to move frum reactive to proactive appraaches. CIAI.

Uyigue, E. and Agho, M. (2007): Coping with climate change and envirommental degradation in the Niger-Deltu of South Nigeria. Community Rescarch and Development Centre (CREDC), Renin.

Vermeulcn, S. J., Campbell, B. M. and Ingram, J. S. I. (2012): Climate Change and Fond Systems. Annual Revicw of Environment and Resources. 37:195-222. 